\title{
Özel Öğrenme Güçlüğü Olan Ortaokul Öğrencilerinin Akıcı Okuma Beceri Düzeylerinin İncelenmesi
}

\author{
Emine BALCl*
}

Öz: Çalışmada, öğrenme güçlüğü tanısı konulmuş ortaokul öğrencilerinin akıcı okuma beceri düzeylerinin cinsiyet, sınıf ve öğrenim görülen okulun sosyoekonomik düzeyine göre incelenmesi amaçlanmıştır. Bu amaçla Ankara ilinden alt, orta ve üst sosyoekonomik düzeyde üç ortaokul belirlenmiştir. Ardından bu okullarda öğrenim gören ve Rehberlik Araştırma Merkezi'nce öğrenme güçlüğü tanısı konulmuş toplamda 47 öğrenciye ulaşılmıştır. Araştırmada öğrencilerin kendi seviyelerine uygun metinler okutulmuş; prozodi puanları, okuma hızı ve doğru okuma yüzdelerine ulaşlarak akıcı okuma beceri düzeyleri belirlenmiştir. Araştırma sonucunda, öğrenme güçlüğü olan bireylerin prozodi becerileri, doğru okuma becerileri ve okuma hızlarının beklenen düzeyden oldukça düşük olduğu, en yüksek seviyede okuma yapan öğrencinin bile ortalamanın altında kaldığı belirlenmiştir. Bu öğrencilerinin akıcı okuma becerileri, sınıf ve cinsiyet değişkenine göre farklılaşmamıştır. Öğrenim görülen okulun sosyoekonomik düzeyine göre ise negatif yönde bir ilişkiye rastlanarak düşük sosyoekonomik düzeydeki öğrencilerin diğerlerine nazaran daha akıcı okuduğu, yine de ortalamaların altında kalarak beklenen akıcı okuma becerisine ulaşamadığı görülmüştür.

Anahtar Sözcükler: Özel Öğrenme Güçlüğü, Okuma Güçlüğü, Disleksi, Akıcı Okuma, Prozodi.

\section{Investigating Fluent Reading Skills of Secondary School Students with Learning Difficulties}

\begin{abstract}
In this study, we aimed to investigate the fluent reading skills of secondary school students who were diagnosed with learning difficulty; the investigation was based on the socioeconomic level of the school, gender, and class. To this end, three secondary schools from lower, middle, and upper socioeconomic levels were chosen from the province of Ankara. Students who were diagnosed with a learning difficulty by the Guidance Research Center were evaluated. A total of 47 students were included in this study. We observed that prosody skills, correct reading skills, and reading speed of the students with learning difficulties were significantly lower than the expected levels. Strikingly, even the students with the highest level of reading skills were below average. Further, there was no difference among the students based on variables such as class and gender. A negative relationship was found between the socioeconomic level of the school and fluent reading skills of these students.
\end{abstract}

Keywords: Learning Difficulties, Reading Difficulties, Dyslexia, Fluent Reading, Prosody. 
Okuma araştırmaları incelendiğinde okuma becerisinin, üç aşamadan oluşan bir modellemeyle öğrenildiği görülmektedir. Bu alanda önemli çalışmaları bulunan Frith (1985) ve Ehri (2005)'ye göre okuma henüz ses-harf ilişkisinin kurulmadığı birinci sınıf öncesi dönemde başlar. Yazıların grafiksel olarak ezberlenip ve tanındığı birinci döneme logografik dönem denir. Ülkemizde 1. sınıfa denk gelen dönemde, öğrenci seslerin görsel olarak temsilleriyle karşılaşır ve ses-harf kodlamasını öğrenir. Harflerin, hecelerin ve kelime öğreniminin yapıldığ arttıkça öğrendikleri kelimeler görsel algı biriminde depolanacak ve daha az çaba ile daha anlamlı ve hızlı okumaya ulaşılacaktır. Kelimelerin ses birimlerine teker teker inilmeden bir bütün olarak tanındığı ve hızlı, otomatik okumanın yapıldığı bu dönem ise ortografik dönem olarak adlandırılmaktadır. Daha az çaba göstererek okumanın doğru, hızlı ve prozodik olarak yapılması akıcı okuma yapılabildiği anlamına gelmektedir. Başka bir deyişle çocuk akıcı okuma becerisini ortografik süreçte yakalayabilmektedir. Öğrencilerin ortografik süreçte akıcı okumanın üç alt basamağı olan prozodik okuma, uygun hızda okuma ve doğru okuma beceri türlerinin hepsine ulaşması beklenmektedir (Rasinski ve Samuels, 2011).

Konuşma esnasında verilmek istenen mesajın; vurgulama, tonlama, anlam gruplarına dikkat ederek yapılandırma gibi süreçlerle dinleyiciye aktarmak mümkün olduğu gibi, okumada da benzer süreçlerle mesaj okuyucuya aktarılmaktadır. Okuyucu da metni noktalama işaretleri ve dilbilgisi aracılığıyla yapılandırmakta, vurgu, tonlama ve cümlenin anlamlı gruplar halinde okumasını sağlamaktadır. Genel olarak okuma sırasında okunan metnin anlamına uygun bir biçimde metni vurgulu, tonlamalı, duygulu ve ritmik okumaya okuma prozodisi denilmektedir (Keskin, Baştuğ ve Akyol, 2013). Okuma prozodisi metnin anlaşılabilmesine katkı sağlayan önemli bir yöntemdir ve akıcı okumanın önemli bir alt basamağıdır (Ateş, 2016; Kaya ve Doğan, 2016).

Prozodi doğal bir süreçle değil aksine verilen uygun bir eğitimle kazanılır. Metni yazarın dilediği gibi okumak bir nevi dramatik becerilerin kullanılmasını gerektirir. Yazarın istediği gibi kahramanları konuşturmak, verilmek istenen duyguyu yansıtmak, noktalama işaretlerine uygun okuma yapmak bir öğretim sürecinde kazandırılabilen becerilerdir. Bu nedenle model alarak yapılan okuma çalışmalarıyla uygun prozodiyi yakalamak mümkündür (Keskin ve diğerleri, 2013). Akıcı okumanın alt basamağı olan okuma prozodisini kazanmış öğrencilerin öncelikle kelimeleri doğru ve uygun hızda okumasını becerebilmeleri gerekmektedir.

Uygun hızda okuma kelimeleri tanıyarak, kodlama ve hecelemeye zaman ayırmadan, enerjisini okuma ve anlamaya vererek otomatik olarak okumaktır. Otomatikleşme olarak adlandırılan bu süreçte geriye dönüş ve kelime tekrarına yer verilmez, heceleme ve gereksiz duruşlar yapılmadan yani akıcı okumanın diğer bir alt basamağı olan doğru okuma yaparak okuma eylemi gerçekleşir. Bu aşamada zihinsel enerji ve çabanın büyük bir kısmı metni okumak ve anlam kurmak için kullanılmaktadır (Akyol, 2005; Keskin ve Baştuğ, 2013).

Öğrencilerden okuma yaparken sesler ve harfler arasında istikrarlı bir ilişki kurmaları, harfleri, heceleri, kelimeleri algılamaları, doğru okuma ile uygun hızda okuma yapabilmeleri ve prozodi kurallarına uygun olarak okuma yapabilmeleri beklenir. Okuma ile ilgili algısal-motor süreçler arasındaki bağı iyi kuramayan bireyin akıcı okuma problemleri gösterdiği bilinmektedir. Özellikle gelişimsel disleksisi olan bireyler yavaş ve yanlış okumalar yapmakta yani akıcı okuyamamaktadır (Bosman, Vonk ve Van Zwam, 2006; Wijnants, Hasselman, Cox, Bosman ve Van Orden, 2012). Özel öğrenme güçlüğüne sahip bu öğrenciler, yukarıda bahsedilen okuma becerilerini (harf, hece ve kelime tanıma, doğru okuma, uygun hizda okuma ve prozodik okuma) etkili bir şekilde kullanamamakta, anlamsız sözcükleri ya da ilk defa karşılaştıkları sözcükleri akranlarına göre daha yavaş ve hatalı okumaktadır (Baydık, 2006). Bunun en büyük sebebi ise özel öğrenme güçlüğü olan öğrencilerin akıcı okuma problemlerinin varlı̆̆ıdır. Bu öğrenciler çok iyi bir sosyal çevreye, iyi bir eğitime ve ortalama zekâya rağmen yetişkinlikte bile akıcı okuma problemleri yaşayabilmektedir (Barton, 2002).

Özel öğrenme güçlüğü olan öğrencilerin en bilinen ve araştırmalarla varlığı ispat edilen özelliği fonolojik süreçlerde yaşadıkları sorunlardır. Bu bireyler henüz ses-harf ilişkisi kurma ve hecelere, kelimelere ulaşarak okuma aşamasında ciddi problemler yaşamaktadır (Balcı, 2015). Disiplinli ve bireye uygun eğitimlerle 
problemlerinin üstesinden gelebilmiş bireyler bile beyinleri yeni karşılaştıkları kelimelerde kodlama sürecine geri dönebilmektedir. Aynı zamanda özel öğrenme güçlüğü olan öğrencilerin okuma esnasında; atlama, ekleme, çıkarma, geriye dönerek okuma, satır kaçırma gibi problemler yaşadığı bilinmektedir (Collette, 1979). Okuma esnasında sıklıkla karşılaşılan bu durumlar okuyucunun hızını, metni doğru okuyabilmesini ve dolayısıyla da prozodisini etkilemektedir. Dünyada özel öğrenme güçlüğü olan öğrencilerin akıcı okuma becerilerini konu alan çalışmalara sıklıkla rastlanmaktadır (Samuels ve Farstrup, 2006). Ana dilleri temel alınarak yapılan bu araştırmalarda kullanılan dilin yapısı ve özel öğrenme güçlüğü arasındaki ilişkiyi ortaya koymaktadır. Türkiye'de ise Türkçe'nin özel öğrenme güçlüğü/disleksisi olan bireyleri nasıl etkilediğini ve bu bireylere nasıl bir öğretim yöntemi kullanılması gerektiği konusunda çalışmalara ihtiyaç duyulmaktadır. Bu nedenle, özel öğrenme güçlüğü tanısı konulmuş öğrencilerin akıcı okuma beceri düzeylerini incelenmeyi amaçlayan bu çalışmanın; alan yazına katkı sunması, eğitimcilere ve bu güçlüğü yaşayan bireylere katkı sağlaması açısından önemli olduğu düşünülmektedir.

\section{Yöntem}

\section{Araştırmanın Modeli}

Özel öğrenme güçlüğü olan öğrencilerin akıcı okuma becerilerini değerlendirmek amacıyla yapılan bu çalışmada, nitel araştırma yöntemlerinden durum çalışması yöntemi kullanılmıştır. Durum çalışması, güncel bir olguyu kendi gerçek yaşam çerçevesi içinde çalışan, 'nasıl' ve 'niçin' sorularını temel alan, araştırmacının kontrol edemediği bir olguyu ya da olayı derinlemesine inceleme olanağı veren bir araştırma yöntemidir (Yıldırım ve Şimşek, 2006). Araştırma, özel öğrenme güçlüğü olan öğrencilerin akıcı okuma becerilerini ortaya koymayı hedeflediği için durum çalışması yöntemi çalışmanın amacına uygun düşmektedir. Bu yöntemle, öğrenme güçlüğü çeken öğrencilerin akıcı okumaya ilişkin var olan becerileri dışarıdan müdahale edilmeden kendi yaşam çerçevesi içinde derinlemesine analiz edilmiştir. Durum çalışması desenlerinden de "Bütüncül çoklu durum deseni" kullanılmıştır. Bütüncül çoklu durum deseninde, birden fazla kendi başına bütüncül olarak algılanabilecek durum bulunmaktadır. Her bir durum kendi içinde bütüncül olarak ele alınmakta ve daha sonra birbirleriyle karşılaştırılmaktadır (Yıldırım ve Şimşek, 2006). Bu çalışmada da özel öğrenme güçlüğü olan öğrencilerin akıcı okuma becerileri cinsiyet, sınıf düzeyleri ve öğrenim gördükleri okulların sosyoekonomik düzeyleri açısından karşılaştırılmıştır.

\section{Çalışma Grubu}

Araştırmanın çalışma grubu amaçlı örnekleme yöntemlerinden maksimum çeşitlilik örneklemesi kullanılarak oluşturulmuştur. Maksimum çeşitlilik örneklemesi, evrende incelenecek problemle ilgili olarak kendi içinde benzeşik ve farklı durumların belirlenerek çalışmanın bu durumlar üzerinden yapılmasıdır. Bu yöntemde amaç, araştırmadaki farklı durumlar arasındaki ortak ya da ayrılan yönleri ortaya çıkarmak ve problemi daha geniş bir çerçevede betimlemektir (Büyüköztürk, Çakmak, Akgün, Karadeniz ve Demirel, 2008). Bu amaçla Ankara İl Milli Eğitim Müdürlüğü'nden uzman görüşleri alınarak belirlenen, il merkezinden üst, orta ve alt sosyoekonomik bölgelerden birer okul seçilmiştir. Çalışmaya başlamadan önce çalışma için gerekli izinler okul idarelerinden alınmış ve bu okulların bağlı bulundukları İlçe Rehberlik Araştırma Merkezleri tarafından 'özel öğrenme güçlüğü' tanısı konulan öğrencilerin listesine okul rehber öğretmenleri ile görüşülerek ulaşılmıştır. Çalışmada toplam 47 öğrenciye ulaşılmıştır. Çalışma grubunun sınıf, cinsiyet ve öğrenim görülen okulun sosyoekonomik düzeyine ait bilgiler Tablo 1'deki gibidir.

Tablo I

Çalı̧ma Grubunun Frekans ve Yüzde Dağılımları

\begin{tabular}{llll}
\hline & & F & \% \\
\hline Sınıf Bilgileri & 5. Sınıf & 12 & 25,5 \\
& 6. Sınıf & 14 & 29,8 \\
& 7. Sınıf & 11 & 23,4 \\
& 8. Sınıf & 10 & 21,3 \\
\hline Öğrenim Görülen Okulun & Yüksek & 16 & 34 \\
Sosyoekonomik Düzeyi & Orta & 16 & 34 \\
\hline
\end{tabular}


Özel Öğrenme Güçlüğü Olan Ortaokul...

\begin{tabular}{llll}
\hline & Düşük & 15 & 31,9 \\
\hline Cinsiyet & Kiz & 23 & 48,9 \\
& Erkek & 24 & 51,1 \\
\hline Toplam & & 47 & 100 \\
\hline
\end{tabular}

Tablo 1 incelendiğinde, çalışma grubunun sınıf, cinsiyet ve öğrenim görülen okulun sosyoekonomik düzeyine göre birbirlerine yakın sayılarda olduğu görülmektedir.

\section{Veri Toplama Araçları}

Araştırmanın verileri video çekimleri kullanarak toplanmıştır. Video çekimi esnasında çalışma grubunun çoğunluğundan gelen kişisel talep üzerine yüzlerinin görünmemesine özen gösterilmiş ve görüntüde, okunan metin yer almış ve okuyucunun sesinin rahatlıkla duyulduğundan emin olunmuştur. Video çekiminin kullanılmasındaki amaç ise tekrar tekrar dinleyerek prozodiye ilişkin becerileri doğru yakalayabilmektir. Toplanan bu veriler ise Keskin ve Baştuğ (2011) tarafından geliştirilen "Prozodik Okuma Ölçeği" ile değerlendirilmiştir.

Prozodik Okuma Ölçeği. Sesli okumada hı, noktalama, tonlama, vurgu, ses özelliği, okuma ritmi, duygu, anlam ünitesiyle okuma (gruplama) ve otomatik kelime tanıma durumlarıla ilgili toplam 15 maddelerden oluşan bir ölçektir. Ölçekten alınabilecek en fazla puan $60^{\prime}$ tır. Toplam puanın \%50'sini alan öğrenciler prozodik olarak yeterli görülmektedir. Keskin ve Başbuğ (2011), ölçeğin kapsam geçerliliğini sağlamak amacıyla uzman görüşüne başvurmuşlardır. Varimax döndürme tekniği kullanılarak yapılan faktör analizinde geliştirilen bu ölçeğin tek faktör etrafında toplandığı görülmüştür. Bu tek faktör, ölçeğe ait toplam varyansın \% 79'unu açıklamaktadır. 15 maddelik ölçeğin iç tutarlılığını belirlemek için Cronbach's Alpha değerine bakılmış ve bu değer 0.981 olarak bulunmuştur. Bulunan bu değer 0.70'in üzerinde olduğundan, yüksek bir güvenirlik göstergesi olarak kabul edilmiştir (Anastasi, 1982).

Öğrencilerin doğru okuma beceri düzeyleri ve okuma hızları ise Akyol, Yıldırım, Ateş, Çetinkaya ve Rasinski (2014) 'nin önerdiği doğru okuma ve okuma hızını ölçme formülleri kullanılarak ölçülmüştür.

\section{Verilerin Toplanması}

Özel öğrenme güçlüğü olan öğrencilerin akıcı okuma becerilerini ölçmek için 5. 6. 7. ve 8. sınıf seviyesine ait Milli Eğitim Bakanlığı tarafından gönderilen ders kitaplarında yer alan bir metin seçilmiştir. Kullanılacak metinler seçilmeden önce öğrencilerin öğrenim gördükleri ders kitaplarının yayınevleri belirlenmiş ve bakanlık tarafından okullara gönderilen diğer yayınevlerine ait ders kitaplarından metinler seçilmiştir. Böylece öğrencilerin metinlerle daha önceden karşılaşabilme durumları ortadan kaldırılmıştır. Metinler seçilirken alandan seçilen iki uzmanın görüşü alınmış ve güçlük derecesi uygun metinler seçilerek çalışmada kullanılmıştır. Öğrenciden bu metni sesli olarak okuması istenmiş ve okumaları video aracılığıyla kaydedilmiştir. Her öğrenci için önceden hazırlanan plan çerçevesinde randevular hazırlanmış ve bireysel olarak çalışma sürdürülmüştür. Öğrencilerin doğru okuma, okuma hızı ve prozodi becerileri video kayıtları incelenerek hesaplanmıştır. Doğru okuma; öğrencilerin 1 dakikada doğru okuduğu kelimelerin yüzdesidir. Öğrencilerin doğru okuma puanlarını hesaplayabilmek için “(doğru okunan kelime sayısı / okunan kelime sayıs1) x 100 = doğru okuma yüzdesi" formülü kullanılmıştır. Doğru okuma yüzdesi ile öğrenciler 'Serbest düzey, öğretim düzeyi ve endişe düzeyi' olmak üzere 3 farklı düzeyde incelenmiştir (Vaughn ve LinanThompson, 2004). Okuma hızı ise öğrencilerin 1 dakikada doğru okuduğu kelime sayısıdır. Okuma hızını hesaplayabilmek içinse "Bir dakikada toplam okunan kelime sayısı - yapılan hata= okuma hızı" formülü kullanılmıştır (Akyol, Yıldırım, Ateş, Çetinkaya ve Rasinski, 2014). Prozodi ise Keskin ve Baştuğ (2011) tarafından geliştirilen 15 maddelik prozodik okuma ölçeği kullanılarak ölçülmüştür.

\section{Verilerin Analizi}

Elde edilen veriler video kayıtları incelenerek öğrencilerin doğru okuma, okuma hızı ve prozodi puanlarına ulaşılmaya çalışılmıştır. Ses kayıtları ve kayıtların yazılı notları güvenirliği arttırmak amacıyla alanda uzman iki araştırmacı tarafından incelenmiş ve tutarlılık sağlanmıştır. SPSS 21 programı kullanılarak veriler analiz edilmiştir. Veri analizinde öğrenme güçlüğü tanısı konulmuş öğrencilerin akıcı okuma beceri 
düzeylerini belirleyen doğru okuma, okuma hızı ve prozodi puanları betimsel istatistikler kullanılarak değerlendirilmiştir. Cinsiyet değişkenine göre akıcı okuma beceri düzeylerindeki farkı belirleyebilmek için bağımsız gruplar için t-testi, sınıf ve sosyoekonomik düzey değişkenlerine göre akıcı okuma beceri düzeylerindeki farkı belirleyebilmek içinse tek yönlü varyans analizi (ANOVA) uygulanmıştır.

Değerlendirme sonucunda özel öğrenme güçlüğü olan öğrencilerin;

1- Akıcı okuma beceri düzeyleri
a- Doğru okuma yüzdeleri
b- Okuma Hizları
c- Prozodi Puanları

2- Cinsiyete göre akıcı okuma düzeyleri

3- Sınıf seviyesine göre akıcı okuma düzeyleri

4- Öğrenim görülen okulun sosyoekonomik düzeyine göre akıcı okuma düzeylerine ait bilgilere ulaşılmıştır.

\section{Bulgular}

\section{Özel Öğrenme Güçlüğü Olan Öğrencilerin Akıcı Okuma Beceri Düzeyleri}

Özel öğrenme güçlüğü tanısı konulmuş öğrencilerin akıcı okuma beceri düzeylerini belirleyebilmek için doğru okuma, okuma hızı ve prozodi puanları değerlendirilmiştir.

Özel öğrenme güçlüğü olan öğrencilerin doğru okuma becerisine ilişkin betimsel istatistikler Tablo 2'deki gibidir.

Tablo II

Özel Öğrenme Güçlüğ̈̈ Olan Öğrencilerin Doğru Okuma Yüzdelerine İlişkin Betimsel İstatistikler

\begin{tabular}{lcccc}
\hline Sinif Düzeyi & $\mathrm{N}$ & En Düşük & En Yüksek & x \\
\hline 5. sinif & 12 & 61,53 & 96,36 & 77,39 \\
\hline 6. sinif & 14 & 50 & 100 & 76,38 \\
\hline 7. sinif & 11 & 55,55 & 94,28 & 77,57 \\
\hline 8. sinif & 10 & 69,49 & 97,24 & 84,89 \\
\hline
\end{tabular}

Tablo 2'deki veriler incelendiğinde özel öğrenme güçlüğü olan öğrencilerin doğru okuma becerisine ilişkin puan ortalamalarının 5 . sınıflarda $\% 77,6$. sınıflarda $\% 76,7$. sinıflarda $\% 77$ ve 8 . sinıflarda ise $\% 84$ puan olduğu görülmektedir.

Özel öğrenme güçlüğü olan öğrencilerin okuma hızlarına ilişkin betimsel istatistikler Tablo 3' deki gibidir.

\section{Tablo III}

Özel Öğrenme Güçlüğ̈̈ Olan Öğrencilerin Okuma Hızlarına İlişkin Betimsel İstatistikler

\begin{tabular}{lcccc}
\hline Okuma Hızı & $\mathrm{N}$ & En Düşük & En Yüksek & $\bar{x}$ \\
\hline 5. sinif & 12 & 39 & 111 & 31,68 \\
\hline 6. sinif & 14 & 15 & 92 & 24,93 \\
\hline 7. sinıf & 11 & 36 & 72 & 15,24 \\
\hline 8. sinif & 10 & 59 & 109 & 18,63 \\
\hline
\end{tabular}

Özel öğrenme güçlüğü olan öğrencilerin okuma hızlarına ilişkin Tablo 3'deki veriler incelendiğinde 5. sınıf öğrencilerinin bir dakikada ortalama 31 kelime, 6. sınıfların 24 kelime, 7. sinıfların 15 kelime ve 8. sinıfların ise 18 kelime okudukları görülmüştür.

Özel öğrenme güçlüğü olan öğrencilerin prozodi puanlarına ilişkin betimsel istatistikler Tablo 4'deki gibidir.

Tablo IV.

Özel Öğrenme Güçlüğü Olan Öğrencilerin Prozodi Puanlarına İlişkin Betimsel İstatistikler

\begin{tabular}{lcccc}
\hline Prozodi Puanları & N & En Düşük & En Yüksek & $\bar{x}$ \\
\hline 5. sinıf & 12 & 13 & 53 & 32,58 \\
\hline
\end{tabular}


Özel Öğrenme Güçlüğü Olan Ortaokul...

\begin{tabular}{lllll}
\hline 6. sinif & 14 & 0 & 48 & 24,21 \\
\hline 7. sinif & 11 & 15 & 33 & 25,72 \\
\hline 8. sinif & 10 & 19 & 57 & 29,80 \\
\hline
\end{tabular}

Özel öğrenme güçlüğü olan öğrencilerin prozodi puanlarına ilişkin Tablo 4'deki veriler incelendiğinde 5 . sinıf öğrencilerinin ortalama prozodi puanının 32,6 . sınıf öğrencilerinin 24,7 . sınıf öğrencilerinin 25 ve 8 . sınıf öğrencilerinin ise 29 olduğu görülmektedir.

\section{Özel Öğrenme Güçlüğü Olan Öğrencilerin Cinsiyet Değişkenine Göre Akıcı Okuma Beceri Düzeyleri}

Özel öğrenme güçlüğü tanısı konulmuş öğrencilerin cinsiyet değişkenine göre akıcı okuma beceri düzeylerindeki farkı belirleyebilmek için bağımsız gruplar için t-testi uygulanmıştır.

Tablo V

Özel öğrenme güçlüğü olan öğrencilerin cinsiyet değişkenine göre $t$ testi sonuçları Tablo 5'deki gibidir.

Özel Öğrenme Güçlü̆̆̈̈ Olan Ö̆̆grencilerin Akıcı Okuma Becerilerine Ait Puanların Cinsiyete Göre t-Testi Sonuçları

\begin{tabular}{|c|c|c|c|c|c|c|}
\hline Anlama Becerisi & Cinsiyet & $\mathrm{N}$ & $\bar{x}$ & ss & $t$ & $\mathrm{p}^{*}$ \\
\hline \multirow[t]{2}{*}{ Doğru Okuma } & $\mathrm{K} 1 \mathrm{z}$ & 23 & 78,41 & 11,8 & \multirow{2}{*}{$-0,155$} & \multirow{2}{*}{0,87} \\
\hline & Erkek & 24 & 79,03 & 15,1 & & \\
\hline \multirow[t]{2}{*}{ Okuma Hızı } & $\mathrm{K}_{12}$ & 23 & 69,6 & 23,59 & \multirow{2}{*}{0,406} & \multirow{2}{*}{0,68} \\
\hline & Erkek & 24 & 66,62 & 6,06 & & \\
\hline \multirow[t]{2}{*}{ Prozodi } & $\mathrm{K}_{12}$ & 23 & 28,95 & 15,06 & \multirow{2}{*}{0,488} & \multirow{2}{*}{0,62} \\
\hline & Erkek & 24 & 26,87 & 14,12 & & \\
\hline
\end{tabular}

Özel öğrenme güçlüğü olan öğrencilerin cinsiyet değişkenine göre akıcı okuma beceri düzeyine ilişkin Tablo 5'deki veriler incelendiğinde doğru okuma, okuma hızı ve prozodi beceri düzeylerinin hiçbirinin cinsiyet değişkenine göre farklılaşmadıkları görülmektedir. Bu sonuçlara göre özel öğrenme güçlüğü olan öğrencilerin akıcı okuma becerisi alt basamağı olan doğru okuma $\left(t_{(47)}=0,155 ; p>0,05\right)$, okuma hızı $\left(t_{(47)}=-0,406\right.$; $\mathrm{p}>0,05)$, ve prozodi $\left(t_{(47)}=0,488 ; p>0,05\right)$ puanları cinsiyete göre anlamlı farklılık göstermemiştir.

\section{Özel Öğrenme Güçlüğü Olan Öğrencilerin Sınıf Seviyesine Göre Akıcı Okuma Beceri Düzeyleri}

Özel öğrenme güçlüğü tanısı konulmuş öğrencilerin sınıf değişkenine göre akıcı okuma beceri düzeylerindeki farkı belirleyebilmek için tek yönlü varyans analizi (ANOVA) uygulanmıştır.

Özel öğrenme güçlüğü olan öğrencilerin sınıf değişkenine göre tek yönlü varyans analizi (ANOVA) sonuçları Tablo 6'daki gibidir.

\section{Tablo VI}

Özel Öğrenme Güçlü̆̆̈̈ Olan Öğrencilerin Akıcı Okuma Becerilerine Ait Puanların Sinıf Değişkenine Göre Tek Yönlü Varyans Analizi (ANOVA) Sonuçları

\begin{tabular}{|c|c|c|c|c|c|c|}
\hline Anlama Becerisi & Sınıf Düzeyi & $\mathrm{N}$ & $\bar{x}$ & ss & $\mathrm{f}$ & $\mathrm{p}^{*}$ \\
\hline \multirow{4}{*}{ Doğru Okuma } & 5. Sinif & 12 & 77,39 & 12,50 & \multirow{4}{*}{0,898} & \multirow{4}{*}{0,45} \\
\hline & 6. Sinif & 14 & 76,38 & 15,58 & & \\
\hline & 7. Sinif & 11 & 77,57 & 15,42 & & \\
\hline & 8. Sinif & 10 & 84,89 & 8,34 & & \\
\hline \multirow{4}{*}{ Okuma Hızı } & 5. Sinif & 12 & 75,75 & 31,68 & \multirow{4}{*}{1,978} & \multirow{4}{*}{0,132} \\
\hline & 6. Sinif & 14 & 76,38 & 24,93 & & \\
\hline & 7. Sinif & 11 & 77,57 & 15,24 & & \\
\hline & 8. Sinif & 10 & 78,5 & 18,63 & & \\
\hline \multirow{4}{*}{ Prozodi } & 5. Sinif & 12 & 32,58 & 17,75 & \multirow{4}{*}{0,854} & \multirow{4}{*}{0,472} \\
\hline & 6. Sinif & 14 & 24,21 & 15,31 & & \\
\hline & 7. Sinif & 11 & 25,72 & 8,49 & & \\
\hline & 8. Sinif & 10 & 29,80 & 14,33 & & \\
\hline
\end{tabular}

Özel öğrenme güçlüğü olan öğrencilerin sınıf değişkenine göre akıcı okuma beceri düzeyine ilişkin Tablo 6'daki veriler incelendiğinde doğru okuma, okuma hızı ve prozodi beceri düzeylerinin hiçbirinin sınıf değişkenine göre farklılaşmadıkları görülmektedir. Bu sonuçlara göre özel öğrenme güçlüğü olan öğrencilerin 
akıcı okuma becerisi alt basamağı olan doğru okuma ( $\mathrm{F}=0,898 ; \mathrm{p}>0.05)$; okuma hızı $(\mathrm{F}=1,978 ; \mathrm{p}>0.05)$ ve prozodi $(\mathrm{F}=0,854 ; \mathrm{p}>0.05)$ puanları sınıf düzeyi değişkenine göre anlamlı farklılık göstermemiştir.

\section{Özel Öğrenme Güçlüğü Olan Öğrencilerin Öğrenim Görülen Okulun Sosyoekonomik Düzeyine Göre Akıcı Okuma Düzeyleri}

Özel öğrenme güçlüğü tanısı konulmuşöğrencilerin öğrenim gördükleri okulların sosyoekonomik düzeyi değişkenine göre akıcı okuma beceri düzeylerindeki farkı belirleyebilmek için tek yönlü varyans analizi (ANOVA) uygulanmıştır. Özel öğrenme güçlüğü olan öğrencilerin öğrenim gördükleri okulların sosyoekonomik düzeyi değişkenine göre tek yönlü varyans analizi (ANOVA) sonuçları Tablo 7'deki gibidir.

Tablo VII

Özel Öğrenme Güçlü̆̆̈̈ Olan Öğrencilerin Akıcı Okuma Becerilerine Ait Puanların Öğrencilerin Öğrenim Gördükleri Okulların Sosyoekonomik Düzeyi Değişkenine Göre Tek Yönlü Varyans Analizi (ANOVA) Sonuçları

\begin{tabular}{|c|c|c|c|c|c|c|}
\hline Anlama Becerisi & Sosyoekonomik Düzey & $\mathrm{N}$ & $\bar{x}$ & ss & $\mathrm{f}$ & $\mathrm{p}^{*}$ \\
\hline \multirow{3}{*}{ Doğru Okuma } & Yüksek & 16 & 66,46 & 10,10 & \multirow{3}{*}{19,933} & \multirow{3}{*}{0,001} \\
\hline & Orta & 16 & 81,89 & 7,65 & & \\
\hline & Düşük & 15 & 88,43 & 11,90 & & \\
\hline \multirow{3}{*}{ Okuma Hizı } & Yüksek & 16 & 49,25 & 20,56 & \multirow{3}{*}{25,498} & \multirow{3}{*}{0,001} \\
\hline & Orta & 16 & 63,93 & 7,32 & & \\
\hline & Düşük & 15 & 92,66 & 20,36 & & \\
\hline \multirow{3}{*}{ Prozodi } & Yüksek & 16 & 17 & 9,33 & \multirow{3}{*}{19,34} & \multirow{3}{*}{0,001} \\
\hline & Orta & 16 & 26,5 & 7,05 & & \\
\hline & Düşük & 15 & 41 & 14,81 & & \\
\hline
\end{tabular}

${ }^{*} \mathrm{p}<0,05$

Özel öğrenme güçlüğü olan öğrencilerin öğrenim gördükleri okulların sosyoekonomik düzeyi değişkenine göre akıcı okuma beceri düzeyine ilişkin Tablo 7 'deki veriler incelendiğinde akıcı okuma becerileri olarak doğru okuma ( $F=19,933 ; \mathrm{p}<0.05)$; okuma hızı $(\mathrm{F}=25,498 ; \mathrm{p}<0.05)$; ve prozodi $(\mathrm{F}=19,34 ; \mathrm{p}<0.05)$ ile sosyoekonomik düzey açısından istatistiksel olarak anlamlı farklılık göstermektedir.

Bu farklılı̆̆ın kaynağını belirlemek için aritmetik ortalama puanları incelendiğinde öğrencilerin doğru okuma puanlarının, yüksek sosyoekonomik düzeydeki okulda öğrenim görenlerin daha düşük ( $\bar{x}=66,46)$, düşük sosyoekonomik düzeyde öğrenim gören çocukların ise daha yüksek $(\bar{x}=88,43)$ olduğu görülmüsstür. Çalışmada öğrencilerin öğrenim gördükleri okulların sosyoekonomik düzeyleri düştükçe öğrencilerin doğru okuma yüzdelerinde artış yaşandığı görülmüştür. Bununla birlikte hiçbir sosyoekonomik düzeyde istenilen doğru okuma puanı düzeyine ulaşılamadığı görülmüştür ( $\bar{x}<\min .100)$.

Çalışmaya katılan öğrencilerin okuma hızına ilişkin aritmetik ortalamaları incelendiğinde ise yüksek

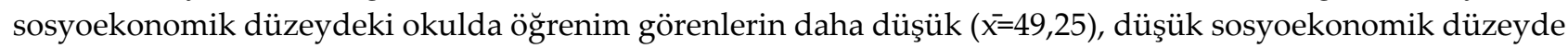
öğrenim gören çocukların ise daha yüksek $(\bar{x}=92,66)$ olduğu görülmüştür. Çalışmada öğrencilerin öğrenim gördükleri okulların sosyoekonomik düzeyleri düştükçe öğrencilerin okuma hızlarında artış yaşandığı görülmüştür. Bununla birlikte hiçbir sosyoekonomik düzeyde istenilen okuma hızı puanı düzeyine ulaşılamadığı görülmüştür ( $\mathrm{x}<\min .118)$.

Özel öğrenme güçlüğü olan öğrencilerin prozodi becerilerine ilişkin aritmetik ortalamaları incelendiğinde ise yüksek sosyoekonomik düzeydeki okulda öğrenim görenlerin daha düşük ( $\bar{x}=17)$, düşük sosyoekonomik düzeyde öğrenim gören çocukların ise daha yüksek ( $\bar{x}=41)$ olduğu görülmüştür. Çalışmada öğrencilerin öğrenim gördükleri okulların sosyoekonomik düzeyleri düştükçe öğrencilerin prozodi puanlarında artış yaşandığ görülmüştür. Elde edilen sonuçlar incelendiğinde öğrencilerin doğru okuma puanları, okuma hızları ve prozodi puanları düşük sosyoekonomik düzey lehine anlamlı biçimde farklılık göstermektedir. Bununla birlikte sadece düşük sosyoekonomik düzeydeki okullarda öğrenim gören öğrencilerin istenilen düzeyde prozodi puanına ulaştı̆̆ı ( $\bar{x}>\min .30)$, diğer sosyoekonomik düzeylerde ise beklenen düzeye ulaşılamadığı görülmüştür $(\bar{x}<\min .30)$. 


\section{Sonuç, Tartışma ve Öneriler}

Özel öğrenme güçlüğü tanısı konmuş öğrencilerin akıcı okuma beceri düzeylerini bazı değişkenlere göre incelemeyi amaçlayan bu çalışmada, öncelikle öğrencilerin akıcı okumanın alt basamakları olan doğru okuma, okuma hızı ve prozodi becerileri incelenmiştir. Torgesen ve Hudson (2006) çalışmalarında okuma güçlügüu yaşayan çocukların akıcı okuma beceri düzeylerinin kendi yaşıtlarına oranla daha düşük olduğunu söylemiştir. Archer, Gleason ve Vachon (2003) ise okuma güçlüğü olan lise öğrencilerinin doğru okuma ve akıcı okuma düzeylerinin istenilen düzeyde olmadığı ve bireye uygun eğitimle bu güçlüklerin üstesinden gelinebileceğinden bahsetmişlerdir. Bu çalışmanın sonucunda da özel öğrenme güçlüğü olan öğrencilerin beklenen doğru okuma yüzdesinin oldukça altında hatta neredeyse yarısında kaldığı görülmüştür. Vaughn ve Linan-Thompson (2004)'a göre doğru okuma yüzdesi \%89 ve altı endişe düzeyi, \%90-\%95 arası öğretim düzeyi, \%96 ve üzeri ise serbest düzeydir. Çalışmada özel öğrenme güçlüğü olan öğrencilerin tamamının doğru okuma yüzdelerinin endişe düzeyinde olduğu görülmektedir.

Öğrencilerin okuma hızlarının da beklenen düzeyin çok aşağısında olduğu belirlenmiştir. Rasinski (2009) çalışmasında ortaokul öğrencilerinin yılsonunda ortalama okuma hızlarına ilişkin 5. sınıfların 118-128 kelime, 6. sinıfların 135-145 kelime, 7. sinıfların 157-167 kelime ve 8. sinıfların ise 166-171 kelime okumaları gerektiğinden söz etmiştir. Çalışmada en yüksek okuma hızına ulaşan öğrencilerin bile beklenen düzeye ulaşamadıkları görülmektedir.

Öğrencilerin prozodik okuma becerileri Keskin ve Baştuğ (2011) tarafından geliştirilen “Prozodik Okuma Ölçeği" ile belirlenmiştir. Bu ölçeğe göre ez az 30 puan alan öğrencinin yeterli prozodik beceriye sahip olduğu düşünülmektedir. Tablo 4'teki ortalama puanlar göz önüne alındığında bu seviyeye yaklaşanların sadece 5 . sınıflar olduğu, diğer sınıf seviyelerinin ise beklenen düzeyin altında kaldıkları görülmektedir. Çalışma sonucunda, özel öğrenme güçlüğü olan öğrencilerin akıcı okuma beceri düzeylerinin istenilen düzeyin çok altında olduğunu söylemek mümkündür.

Çalışmada özel öğrenme güçlügü olan öğrencilerin akıcı okuma beceri düzeylerinin sınıf değişkenine göre farklılaşmadığı görülmüştür. Bunun en önemli sebebinin ise özel öğrenme güçlügünün sınıf seviyesine göre değil bireyin seviyesine göre değiştiğidir. Her bireyin kendine özgü bir düzeyi vardır. Ortaokulda öğrenim gören bir öğrencinin okuma becerileri 4. sınıf seviyesindeki bir öğrencinin gösterdiği performansa denk gelebilirken, başka bir öğrencininki kendi seviyesinden sadece bir iki sınıf aşağısında yer alabilir. Nitekim çalışmalar da bunu kanıtlamakta, ortaokul seviyesinde heceleme ve kodlamada güçlük yaşayan öğrencilerin varlığından söz etmekle birlikte (Mercer, Campbell, Miller, Mercer ve Lane, 2000; Saenz ve Fuchs, 2002) ilkokul seviyesinde kodlamada problem yaşayan, akıcı okuyamayan özel öğrenme güçlüğü olan öğrencilerin varlığından da söz etmektedirler (Balcı ve Çayır, 2017; Chard, Vaughn ve Tyler, 2002; Hitchcock, Prater ve Dowrick, 2004; O'connor ve diğerleri, 2002). Roberts, Torgesen, Boardman ve Scammacca (2008) ise çalışmalarında ilkokul, ortaokul ve lisede öğrenim gören özel öğrenme güçlüğü olan öğrenciler arasında yaptığı çalışmada, tüm sınıf seviyelerinde akıcı okuma düzeylerinde problemlere rastlamışlardır. Çalışmada elde edilen sonuçlar göz önüne alındığında, eğitimcilerin özel öğrenme güçlüğü olan öğrencilerin bireysel eğitim ihtiyaçlarını iyi belirleyerek gereken eğitsel müdahaleleri zamanında yapmaları gerektiği tavsiye edilmektedir. Bu öğrenciler sınıflarındaki yaşıtlarla aynı seviyede olmamakta ve her sene bu açık artarak çoğalmaktadır. Akıcı okumanın, okuduğunu anlama ile ilişkisinin güçlü olduğu çalışmalarla da kanıtlanmıştır (Başaran, 2013; Baştuğ ve Keskin, 2012; Çetinkaya, Ateş ve Yıldırım, 2016). Okuma becerisindeki amaç okuduğunu anlamaksa, bu öğrencileri bu seviyeye getirmek için daha ilk yıllarda gerekli önlemin alınması gerekmektedir.

Çalışmanın bir diğer sonucu ise özel öğrenme güçlüğü olan öğrencilerin akıcı okuma beceri düzeylerinin cinsiyet değişkenine göre farklılaşmadığıdır. Çalışmalar da gösteriyor ki, özel öğrenme güçlügü olan bireyler sadece akıcı okuma beceri düzeyinde değil okuma ve yazmanın hiçbir alanında cinsiyete göre farklılaşma yaşamamaktadır. Beaton (2002) ve Chan, Ho, Tsang, Lee ve Chung (2007) özel öğrenme güçlüğü olan öğrenciler üzerinde yaptıkları çalışmalarda okuma ile ilgili bilişsel yeteneklerde cinsiyet farklılığından söz edemediklerini belirtmişlerdir. Bunun aksini iddia eden çalışmaların varlığı söz konusu olmakla birlikte bu 
çalışmalar Shaywitz (2003)'e göre erkeklerin cinsiyete özgü davranışlarının şüphe uyandırmasından kaynaklanmaktadır ve tam anlamılla cinsiyetin özel öğrenme güçlüğü üzerinde etkisinden söz etmek mümkün olmamaktadır.

Özel öğrenme güçlüğü olan öğrencilerin akıcı okuma beceri düzeylerinin öğrenim gördükleri okulların sosyoekonomik düzeylerine göre incelenmesi, çalışmanın cevap aradığı bir diğer sorundur. Literatürde yer alan okuma başarısı ile öğrenciye sunulan sosyoekonomik düzey arasındaki pozitif düzeydeki anlamlı ilişkinin aksine çalışmada okulların sosyoekonomik düzeyleri ve özel öğrenme güçlüğünde akıcılık ile ilgili negatif yönde bir ilişki bulunmuştur (Arıcı ve Altıntaş, 2014; Coşkun, 2003; Çiftçi ve Temizyürek, 2008). Düşük sosyoekonomik düzeyde öğrenim gören özel öğrenme güçlüğü olan öğrencilerin diğer okullarda öğrenim gören öğrencilere göre daha yüksek düzeyde akıcı okuma performansı göstermelerine karşılık bu performanslarının yine de beklenen düzeyin çok altında olduğu sonucuna ulaşılmıştır. Literatürde buna yakın bir sonuçla karşılaşılmamasına rağmen bu durum, düşük sosyoekonomik düzeye sahip olduğu belirlenen ve seçilen okulun sınıf, rehber ve özel eğitim öğretmenlerinin başarılı performanslarına bağlanabilir.

Çalışma süresince araştırmacı tarafından da görüldüğü üzere bu öğrencilerin tanılanması, kaynaştırma eğitimine alınması ve verilen eğitim süreçlerinde ciddi problemlerle karşılaşılmaktadır (Balcı, 2015). Özel öğrenme güçlüğü çektiği düşünülen öğrencilerin zamanında tanılanması, bireysel eğitim ihtiyaçları belirlenerek kişiye özgü, istikrarlı bir eğitimle problemlerinin üstesinden gelmelerinin sağlanması oldukça önemlidir. Burada aile, okul öncesi öğretmeni, sınıf öğretmeni, Türkçe öğretmeni, rehber öğretmen ve özel eğitim öğretmenleri ile birlikte okul yönetiminin koordinasyonu oldukça önemlidir. Bu alanda toplumsal farkındalığı arttıracak sosyal ve akademik çalışmaların sayısı ve niteliğinin artması gerektiği düşünülmektedir.

Araştırma belirlenen okullarla ve bu okullarda öğrenim gören öğrenme güçlüğü olan öğrencilerle sınırlıdır. Türkiye'yi temsil edebilecek daha kapsamlı bir çalışma ile genel bir fikre sahip olmak mümkün olabilecektir. Öğrenme güçlüğünün Türkiye'deki varlığını ortaya koyan ve bu güçlükle mücadele etmekte yararlı olabilecek eğitsel yöntemlere ilişkin çalışmaların bu alana katkısı büyük olacaktır. Altuntaş (2010) 'ın da belirttiği gibi öğretmenler öğrenme güçlügüne ilişkin neler yapabilecekleri konusunda belirsiz bırakılmış durumdadır. Araştırmacıların ışık tutacağı çalışmalarla bu öğrencilere nasıl eğitim vermeleri gerektiği konusundaki kafa karışıklıkları giderilmelidir. Böylece öğretmenlerden bu öğrencilere yönelik bireysel eğitim vermelerini istemek mümkün olacaktır. Öğrenme güçlüğü olan öğrencilerin her birinin ayrı olan bireysel eğitim ihtiyaçlarına yönelik uygulanan uygun eğitim yöntemleriyle güçlüklerinin üstesinden gelebilmeleri beklenebilir.

\section{Kaynaklar}

Akyol, H. (2005). Türkçe ilkokuma yazma öğretimi. Ankara: Pegem A Yayıncllık.

Akyol, H., Yıldırım, K., Ateş, A., Çetinkaya, Ç. ve Rasinski, T. (2014). Okumayı Değerlendirme. Ankara: Pegem A Yayınları.

Altuntaş, F. (2010). Sınıf öğretmenlerinin disleksiye ilişkin bilgileri ve dislektik öğrencilere yönelik çalışmaları (Yayımlanmamış yüksek lisans tezi). Hacettepe Üniversitesi, Ankara.

Anastasi, A. (1982). Psychological testing. New York: McMillan Publishing Co.

Archer, A. L., Gleason, M. M. ve Vachon, V. L. (2003). Decoding and fluency: Foundation skills for struggling older readers. Learning disability quarterly, 26(2), 89-101.

Arıcı, Ö. ve Altıntaş, Ö. (2014). PISA 2009 okuma becerileri yeterliklerinin sosyoekonomik alt yapı ve okul öncesi eğitime katılım açısından incelenmesi "Türkiye Örneği”. Ankara Üniversitesi Ĕ̆itim Bilimleri Fakültesi Dergisi, 47(1), 423-448.

Ateş, A. (2016). Ortaokul öğrencilerinin prozodik okuma becerileri ile okuma kaygıları arasındaki ilişkinin incelenmesi. International Journal of Languages' Education and Teaching, 4(3), 207-216. 
Balcı, E. (2015). Amerika Birleşik Devletleri'nde disleksili bireylere uygulanan eğitim ve öğretim programlarının Türkiye'de yapılan çalışmalara katkısı açısından değerlendirilmesi (Doktora tezi). Gazi Üniversitesi, Ankara.

Balcı, E. ve Çayır, A. (2017). Disleksi riski taşıyan 4. sınıf öğrencisinin fonolojik farkındalığının arttırılmasında çoklu duyusal öğrenme'nin etkisi. Ana Dili Eğitimi Dergisi, 5(2), 201-216.

Barton, S. (2002). Warning signs of dyslexia. 13.08.2019 tarihinde https://bartonreading.com/pdf/Dys-warningsigns1.pdf adresinden erişildi.

Başaran, M. (2013). Okuduğunu anlamanın bir göstergesi olarak akıcı okuma. Kuram ve Uygulamada Ĕ̆itim Bilimleri, 13(4), 2277-2290.

Baştuğ, M. ve Keskin, H. K. (2012). Akıcı okuma becerileri ile anlama düzeyleri (basit ve çıkarımsal) arasındaki ilişki. Ahi Evran Üniversitesi Kırşehir Ĕ̆itim Fakültesi Dergisi, 13(3), 227-244.

Baydık, B. (2006). Okuma güçlüğü olan çocukların sözcük okuma becerileri. Ankara Üniversitesi Ĕgitim Bilimleri Fakültesi Özel Ĕ̆itim Dergisi, 7(1), 29-36.

Beaton, A. A. (2002). The relation of planum temporale asymmetry and morphology of the corpus callosum to handedness, gender, and dyslexia: A review of the evidence. Brain and Language, 60(2), 255-322.

Bosman, A. M., Vonk, W. ve Van Zwam, M. (2006). Spelling consistency affects reading in young Dutch readers with and without dyslexia. Annals of Dyslexia, 56(2), 271-300.

Büyüköztürk, Ş., Çakmak, E. K., Akgün, Ö. E., Karadeniz, Ş. ve Demirel, F. (2008). Bilimsel araştırma yöntemleri. Ankara: PegemA.

Chan, D. W., Ho, C. S. H., Tsang, S. M., Lee, S. H. ve Chung, K. K. (2007). Prevalence, gender ratio and gender differences in reading related cognitive abilities among Chinese children with dyslexia in Hong Kong. Educational Studies, 33(2), 249-265.

Chard, D. J., Vaughn, S. ve Tyler, B. J. (2002). A synthesis of research on effective interventions for building reading fluency with elementary students with learning disabilities. Journal of Learning Disabilities, 35(5), 386-406.

Collette, M. A. (1979). Dyslexia and classic pathognomic signs. Perceptual and Motor Skills, 48(3), 1055-1062.

Coşkun, E. (2003). Çeşitli değişkenlere göre lise öğrencilerinin etkili okuma becerileri ve bazı öneriler. Türklük Bilimi Araştırmaları, (13), 101.

Çetinkaya, F. Ç., Ateş, S. ve Yıldırım, K. (2016). Prozodik okumanın aracılık etkisi: Lise düzeyinde okuduğunu anlama ve akıcı okuma arasındaki ilişkilerin incelenmesi. Turkish Studies International Periodical for the Languages, Literature and History of Turkish or Turkic, 11(3), 809-820.

Çiftçi, Ö. ve Temizyürek, F. (2008). İlköğretim 5. sınıf öğrencilerinin okuduğunu anlama becerilerinin ölçülmesi. Mustafa Kemal Üniversitesi Sosyal Bilimler Enstitüsü Dergisi, 5(9), 109-129.

Ehri, L. C. (2005). Learning to read words: Theory, findings, and issues. Scientific Studies of reading, 9(2), 167188.

Frith, U. (1985). Beneath the surface of developmental dyslexia. Surface dyslexia, 32, 301-330.

Hitchcock, C. H., Prater, M. A. ve Dowrick, P. W. (2004). Reading comprehension and fluency: Examining the effects of tutoring and video self-modeling on first-grade students with reading difficulties. Learning Disability Quarterly, 27(2), 89-103.

Kaya, D. ve Doğan, B. (2016). Birinci sınıf öğrencilerinin akıcı okumalarının değerlendirilmesi. Turkish Studies-International Periodical for the Languages, 11(3), 1308-2140.

Keskin, H. K. ve Baştuğ, M. (2013). Geçmişten günümüze akıcı okuma. Türkiye Sosyal Araştırmalar Dergisi, 171(171), 189-208. 
Keskin, H. K., Baştuğ, M. ve Akyol, H. (2013). Sesli okuma ve konuşma prozodisi: İlişkisel bir çalışma. Mersin Üniversitesi Ĕ̆itim Fakültesi Dergisi, 9(2), 168-180.

Mercer, C. D., Campbell, K. U., Miller, M. D., Mercer, K. D. ve Lane, H. B. (2000). Effects of a reading fluency intervention for middle schoolers with specific learning disabilities. Learning Disabilities Research $\mathcal{E}$ Practice, 15(4), 179-189.

O'connor, R. E., Bell, K. M., Harty, K. R., Larkin, L. K., Sackor, S. M. ve Zigmond, N. (2002). Teaching reading to poor readers in the intermediate grades: A comparison of text difficulty. Journal of Educational Psychology, 94(3), 474.

Rasinski, T. (2009). Effective teaching of reading: From phonics to fluency. Recuperado el día, 3(1), 1-55.

Rasinski, T. V. ve Samuels, S. J. (2011). Reading fluency: What it is and what it is not. What research has to say about reading instruction, 23(2), 94-14.

Roberts, G., Torgesen, J. K., Boardman, A. ve Scammacca, N. (2008). Evidence-based strategies for reading instruction of older students with learning disabilities. Learning Disabilities Research \& Practice, 23(2), 6369.

Saenz, L. M. ve Fuchs, L. S. (2002). Examining the reading difficulty of secondary students with learning disabilities: Expository versus narrative text. Remedial and Special Education, 23(1), 31-41.

Samuels, S. J. ve Farstrup, A. E. (2006). What research has to say about fluency instruction. International Reading Association. US.

Shaywitz, S. (2003). Overcoming dyslexia: A new and complete science-based program for reading problems at any level. New York: Alfred A. Knopf.

Torgesen, J. K. ve Hudson, R. F. (2006). Reading fluency: Critical issues for struggling readers. What research has to say about fluency instruction. International Reading Association: Newark.

Vaughn, S. ve Linan-Thompson, S. (2004). Research-based methods of reading instruction, grades K-3. Association for Supervision and Curriculum Development: USA.

Wijnants, M. L., Hasselman, F., Cox, R. F. A., Bosman, A. M. T. ve Van Orden, G. (2012). An interactiondominant perspective on reading fluency and dyslexia. Annals of dyslexia, 62(2), 100-119.

Yıldırım, A. ve Şimşek, H. (2006). Sosyal Bilimlerde Nitel Araştırma Yöntemleri. Ankara: Seçkin Yayıncılık. 


\section{EXTENDED ABSTRACT}

\section{Introduction}

Reading skills are acquired at three stages. According to Frith (1985) and Ehri (2005), who conducted important research in this field, graphemes are memorized and recognized graphically first. Then, letters, syllables, and vocabulary are recognized. Finally, students can follow the sound units of words as a whole and thereafter, can read quickly, accurately, and automatically. Within this period, the students are expected to be capable of the three types of fluent reading, namely prosodic reading, proper reading, and correct reading (Rasinski and Samuels, 2011). Individuals who cannot establish the connection between the perceptual-motor processes related to reading are considered to have fluent reading problems. Particularly, individuals with developmental dyslexia tend to read slowly and incorrectly, and cannot read fluently (Bosman, Vonk, \& van Zwam, 2006; Wijnants, Hasselman, Cox, Bosman, \& Van Orden, 2012). Although studies on fluent reading skills of students with learning difficulty have been widely conducted in most countries, it is limited in Turkey. Therefore, in this study we aim to analyze the fluent reading skill levels of students with learning difficulty in Turkey.

\section{Method}

We used the case study method, which was one of the qualitative research methods. The fluent reading skill levels of secondary school students who were diagnosed with learning difficulty were evaluated based on the socioeconomic level of the school, gender, and class. To this end, three secondary schools from lower, middle, and upper socioeconomic levels were chosen from the province of Ankara by using the maximum diversity sampling method. Thereafter, students who were studying in these schools and were diagnosed with a learning difficulty by the Guidance Research Center were assessed. A total of 47 students were included in this study. The research was conducted separately for each student and the students were given the appropriate texts. A video camera was used when the students were reading and prosody scores, reading speed, and correct reading percentages were analyzed; thereafter, the fluent reading skill level was determined. For data analysis, descriptive techniques were used. Statistical analyses were performed using $t$ test and analysis of variance (ANOVA) for independent samples.

\section{Results}

We found that prosody skills, correct reading skills, and reading speed of the students with learning difficulties were significantly lower than the expected levels; even the students with the highest level of reading were below the average. The fluent reading skills of secondary school students with learning difficulties did not differ based on variables such as class level and gender. A negative relationship was found between the socioeconomic level of the school and fluent reading skills of these students. Students at a low socioeconomic level were found to be more fluent than the others; nevertheless, they could not reach the expected level of fluent reading skills.

\section{Conclusion}

In this study, we found that the fluent reading skill levels of the students with learning difficulties did not differ according to the class. The reason is that learning difficulties vary according to the reading level of the individual, not the pre-determined level of the class. An individual with learning difficulties has a specific level. The reading skills of a student in a secondary school may correspond to the performance of a student from class 4. Indeed, several studies have suggested this and mentioned the existence of students who have difficulty in coding and fluency at both secondary and primary levels (Balcı \& Çayır, 2017; Chard, Vaughn, \& Tyler, 2002; Hitchcock, Prater, \& Dowrick, 2004; Mercer, Campbell, Miller, Mercer, \& Lane, 2000; O'connor et al., 2002; Saenz \& Fuchs, 2002). We also showed that the fluent reading skills of the students with learning difficulties do not differ according to gender. Studies have also shown that individuals with learning difficulty can differ not only in fluent reading skills but also in any area of reading and writing (Beaton, 2002; Chan, Ho, Tsang, Lee ve Chung, 2007; Shaywitz, 2003). In this study, a negative relationship was observed between the socioeconomic levels of schools and reading fluency. Although students with low socioeconomic status 
showed higher levels of fluent reading, it was concluded that these performances were still well below the expected level. This may be attributed to the successful performance of the teachers, counselors, and special education teachers of the school that has a low socioeconomic level. It is important that the students who are thought to have learning difficulties are diagnosed in time, to determine the individual training needs and to overcome the specific education-related problems. At this point, the coordination of family, teachers, and school management is important. An increase in the number and quality of social and academic studies in this area is required. 